\title{
Miniaturization of a Quasi-Servo Valve and Its Application to Positon Control of a Rubber Artificial Muscle with Built-in Sensor
}

\author{
Yoshinori Moriwake $^{1}$, Shujiro Dohta ${ }^{1, a}$, Tetsuya Akagi ${ }^{1}$ and So Shimooka ${ }^{1}$ \\ ${ }^{1}$ Okayama University of Science, 1-1, Ridai-cho, Kita-ku, Okayama, Japan
}

\begin{abstract}
Nowadays, the care and welfare pneumatic devices to support a nursing care and a self-reliance of the elderly and the disabled are actively researched and developed by many researchers. These wearable devices require many actuators and control valves for multi degrees of freedom. The total weight and volume of the wearable devices increases according to the degree of freedom. Our final goal is to develop a compact wearable actuator with built-in sensor, controller and control valve and to apply it to a wearable assisted device. In our previous study, a small-sized quasi-servo valve which consists of two on/off control valves and an embedded controller was developed. In this study, the quasi-servo valve composing of much smaller-sized ( $40 \%$ in mass, $42 \%$ in volume) on/off valves is proposed and tested. In addition, the rubber artificial muscle with an ultrasonic sensor as a built-in displacement sensor is proposed and a position control of the muscle is carried out using the tested tiny valve and built-in sensor. As a result, it was confirmed that the position control of the muscle can be realized using the tested ultrasonic sensor.
\end{abstract}

\section{Introduction}

Today, the care and welfare pneumatic devices to support a nursing care and a self-reliance of the elderly and the disabled are actively researched and developed by many researchers [1] to [5]. These wearable devices require many actuators and control valves for multi degrees of freedom and precise control performance of the device. The total weight and volume of the wearable devices increases according to the degree of freedom. Therefore, we aim to develop a compact and low-cost servo valve and a wearable actuator built-in sensor. In our previous studies [6] to [8], a small-sized, light-weight and inexpensive pressure control type quasi-servo valve which consists of two on/off control valves using a low-cost embedded controller and a pressure transducer was proposed and tested. In this paper, a quasi-servo valve by using the much smaller, lighter and inexpensive on/off control valves is produced and tested. In addition, as an application of the tested valve, a position control of a rubber artificial muscle is carried out by using the tested quasi-servo valve and an ultrasonic sensor as a displacement sensor. The ultrasonic sensor is installed in the rubber artificial muscle to develop a compact wearable actuator with built-in sensor. The control performance of the muscle is shown and the usefulness of the tested built-in sensor is discussed.

\footnotetext{
${ }^{\mathrm{a}}$ Corresponding author : dohta@are.ous.ac.jp
} 


\section{Quasi-Servo Valve}

Figures 1 and 2 show the schematic diagram and the view of the quasi-servo valve, respectively. The valve consists of two on/off control valves (SMC Co. Ltd., S070C-SDG-32) whose both output ports are connected to each other. One valve is used as a switching valve to supply or exhaust, and the other is used as a PWM control valve that can adjust output flow rate like a variable fluid resistance [6]. The size of the on/off valve is $12 \times 33 \times 7 \mathrm{~mm}$, and the mass is only $6 \mathrm{~g}$. The previous on/off valve (Koganei Co. Ltd., G010HE-1) was $33 \times 20 \times 10 \mathrm{~mm}$, and the mass was $15 \mathrm{~g}$ [6]. The proposed valve is $58 \%$ smaller and $60 \%$ lighter than the previous valve. The maximum output flow rate is $15 \mathrm{liter} / \mathrm{min}$ at the supply pressure of $500 \mathrm{kPa}$.

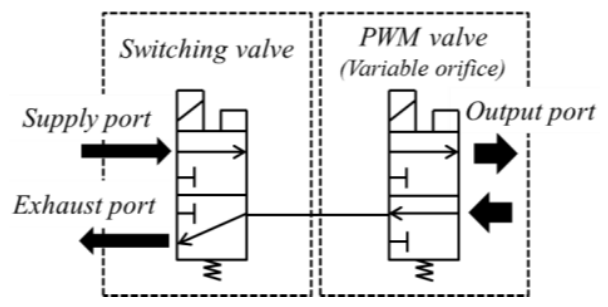

Figure 1. Schematic diagram of quasi-servo valve.

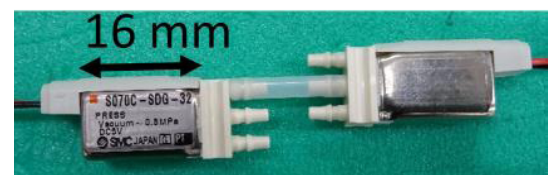

Figure 2. View of quasi-servo valve.

\section{Artificial Rubber Muscle with Built-In Displacement Sensor}

As a built-in displacement sensor of the rubber artificial muscle, an ultrasonic sensor was selected, because the ultrasonic sensor has many advantages that it can measure the displacement by noncontacting and is a low-cost sensor. Figures 3 and 4 show a schematic diagram of the system and a view of a rubber artificial muscle (FESTO Co. Ltd., MXAM-10-AA) with a built-in sensor and an embedded controller, respectively. The original length of rubber artificial muscle is $250 \mathrm{~mm}$ and the inner diameter is $10 \mathrm{~mm}$. The stroke of the muscle is about $50 \mathrm{~mm}$ in the case when the supply pressure of $500 \mathrm{kPa}$ is applied. The tested ultrasonic sensor is rebuilt by using the sensor on the market (Parallax Inc. Ltd., 28015). The transmitter and receiver on the sensor are changed smaller ones as shown in Fig.8 on the right side (the transmitter: Nippon Ceramic Co. Ltd., T4008A1) and on the left side (the receiver: Nippon Ceramic Co. Ltd., R4008A1), respectively. The measuring principle is well known as follows. The distance is estimated by the time until the ultrasonic wave reaches at the receiver from the transmitter. This time is counted by an embedded controller (Renesas Co. Ltd., SH7125). The distance between the transmitter and the receiver can be obtained by using the velocity of sound and the time interval; counting value.

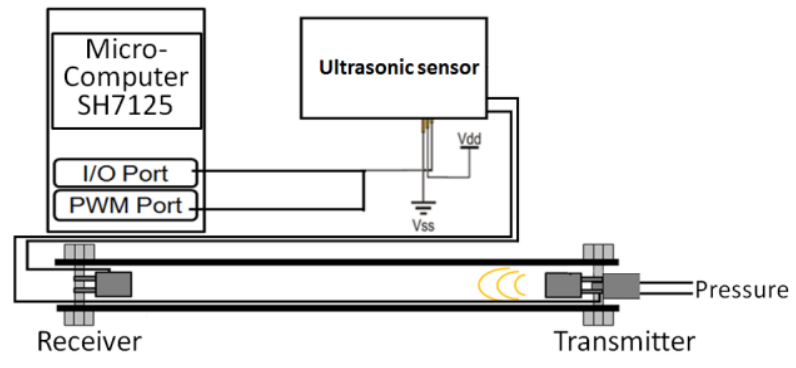

Figure 3. Schematic diagram of artificial muscle with built-in sensor. 


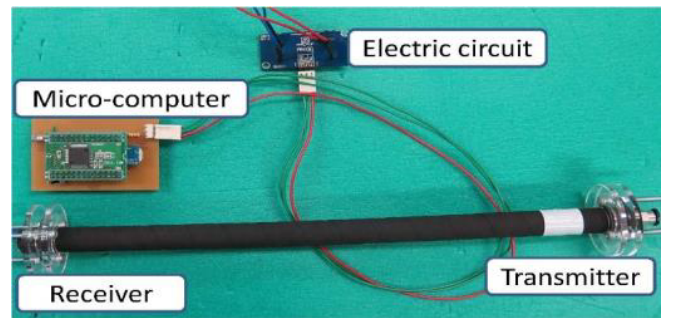

Figure 4. View of rubber artificial muscle with built-in sensor.

Figure 5 shows the relation between the counting value and the measured length of the rubber artificial muscle. The counting value was obtained by the tested built-in ultrasonic sensor and the measured length was obtained by the potentiometer. In the experiment, the artificial muscle was pressurized from 200 to $500 \mathrm{kPa}$ every $50 \mathrm{kPa}$. From Fig.5, it can be seen that the relation between the sensor output and the length of the muscle is linear even if the rubber muscle is pressurized. This result means that the tested ultrasonic sensor is useful as a built-in displacement sensor of the rubber artificial muscle. From the result, the relation between the length $L_{m}[\mathrm{~mm}]$ and the counting value $C_{m}[-]$ can be expressed by the following equation.

$$
L_{m}=0.197 C_{m}+129
$$

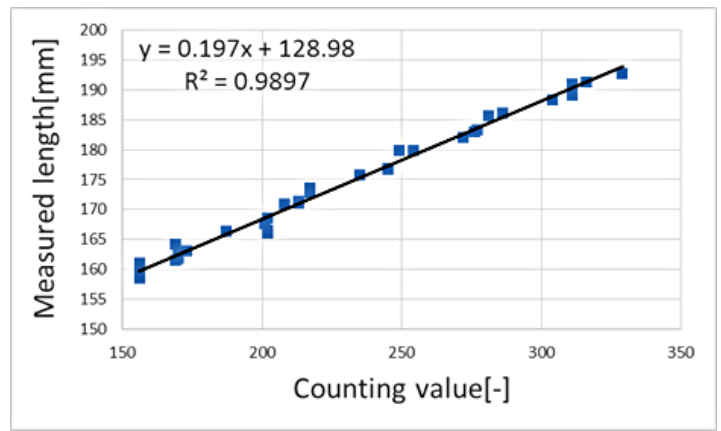

Figure 5. Relation between applied pressure and length of muscle.

\section{Position Control of Artificial Rubber Muscle with Built-In Sensor Using Quasi-Servo Valve}

Figures 6 and 7 show the schematic diagram and the view of the position control system of the tested rubber artificial muscle with built-in sensor, respectively. The control system consists of the tested quasi-servo valve, the tested rubber artificial muscle and an embedded controller. In addition, the potentiometer is connected with the tested muscle in order to measure the true displacement as a monitor. The position control is done as follows. First, the embedded controller counts the time of the output signal from the tested ultrasonic sensor through I/O port. The embedded controller also calculates the length of the muscle from the counted value mentioned above. The error between the measured displacement and the reference displacement is calculated by the controller and the control input for the quasi-servo valve is also calculated based on a control scheme. Finally, the control input is applied to the quasi-servo valve as PWM signal and on/off signal for two on/off valve in quasiservo valve. 


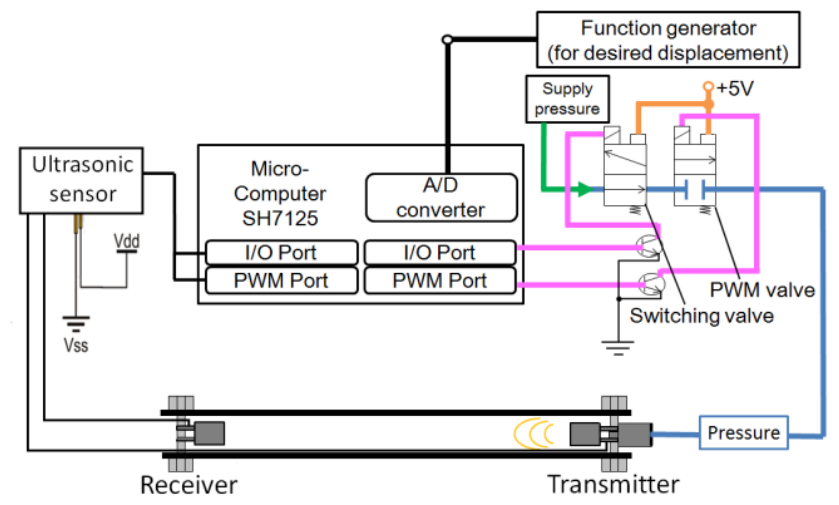

Figure 6. Schematic diagram of position control system.

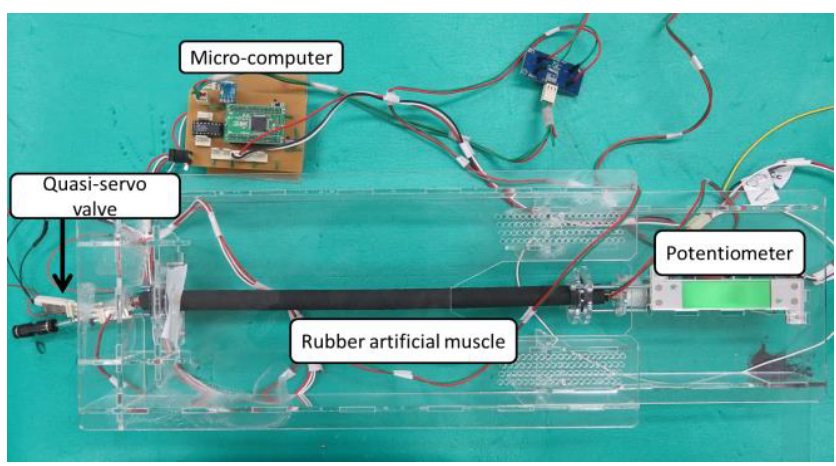

Figure 7. View of the position control system.

Figure 8 shows the transient response of displacement of the rubber artificial muscle with built-in displacement sensor. In the experiment, the desired sinusoidal position with the offset of $25 \mathrm{~mm}$, the amplitude of $10 \mathrm{~mm}$ and the frequency of $0.1 \mathrm{~Hz}$ was applied to the control system as a reference. As a feedback displacement signal, the output signal from the potentiometer was used. The supply pressure is $500 \mathrm{kPa}$. PD control scheme expressed by following equations was used.

$$
\begin{array}{r}
u_{d}=K_{p} e_{c}+K_{d} \Delta e_{c} \\
u=\left|u_{d}\right|+20
\end{array}
$$

Where $u_{d}, K_{p}(=65 \% / \mathrm{mm}), e_{c}, K_{d}(=35 \% / \mathrm{mm}), \Delta e_{c}$ and $u$ mean the control input, the proportional gain, the error from the reference, the derivative gain, difference of error and input duty ratio to the PWM valve, respectively. As mentioned above, the switching valve switches to supply if $u_{d}>0$, and to exhaust in other case. In Fig.8, the blue, red and green lines show the reference displacement, the true displacement measured by potentiometer and the measured displacement by using ultrasonic sensor, respectively. From Fig.8, it can be observed that the measured displacement by a potentiometer can track the reference displacement and that the measured displacement using the ultrasonic sensor is a little larger than the true displacement while the displacement is increasing: the air is being supplied. This is because the velocity of the sound wave is increased by the air supply as shown in Fig.6, and the length of the muscle is estimated shorter and consequently the contracted displacement becomes larger. Figure 9 shows the transient response of the displacement of the rubber muscle using the signal from ultrasonic sensor as a feedback signal. From Fig.9, it can be found that the measured displacement using ultrasonic sensor can track well the reference displacement. However, the displacement is a little larger than the true displacement while the displacement is 
increasing and the displacement is much larger than the true displacement when the displacement is decreasing: the air is being exhausted. This phenomenon can be explained as same as mentioned above. But, its difference is larger than the case when the air is supplied. The investigation for this phenomenon and its compensation for the position control are our future works. However, it is concluded that the tested ultrasonic sensor can be used as a built-in displacement sensor for the rubber artificial muscle.

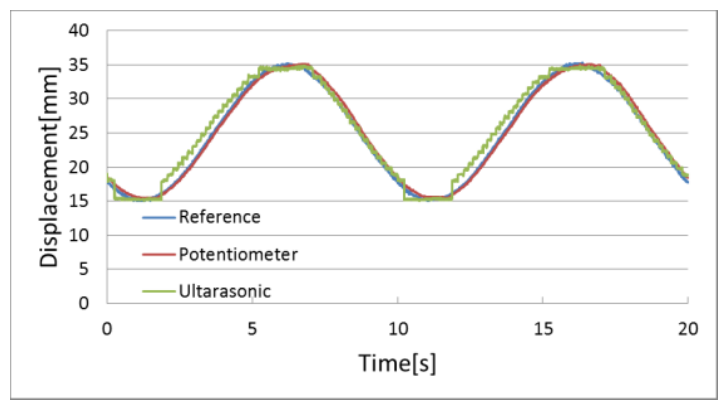

Figure 8. Position control using the potentiometer as a feedback signal.

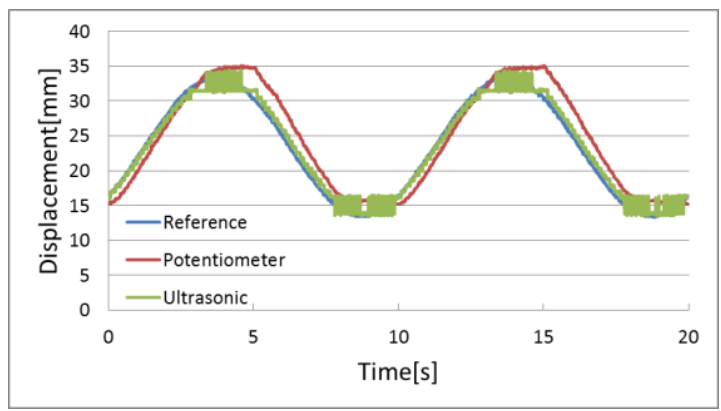

Figure 9. Position control using the ultrasonic sensor as a feedback signal.

\section{Conclusions}

This study can be summarized as follows. The new small-sized quasi-servo valve using a tiny on/off valve which is $58 \%$ smaller and $60 \%$ lighter than previous one was produced and tested. In addition, the rubber artificial muscle using the built-in ultrasonic sensor was proposed and tested. The measuring system of the tested sensor using the embedded controller was also proposed and tested. In order to confirm the effectiveness of the tested sensor, the relation between the counting value in the tested sensor and true displacement measured by the potentiometer was investigated. And the position control system that consists of the rubber artificial muscle with built-in displacement sensor, the small-sized quasi-servo valve and an embedded controller was proposed and tested. As a result, it was confirmed that the ultrasonic sensor could be used as a built-in sensor of the rubber artificial muscle.

\section{Acknowledgements}

This research was supported by the Ministry of Education, Culture, Sports, Science and Technology of Japan through a Financial Assistance Program for QOL Innovative Research (2012-2016). 


\section{References}

1. T. Noritsugu, M. Takaiwa and D. Sasaki, Development of Power Assist Wear Using Pneumatic Rubber Artificial Muscles, Journal of Robotics and Mechatronics, 21, 607-613 (2009)

2. N. Hogan and H. I. Krebs, Interactive robots for neuro-rehabilitation, Restorative Neurology and Neuroscience, 22, 349-358 (2004)

3. H. Kobayashi, T. Shiban and Y. Ishida,Realization of all 7 motions for the upper limb by a muscle suit, Journal of Robotics and Mechatronics, 16, 504-512 (2004)

4. M. Ishii, K. Yamamoto and K. Hyodo, Stand-Alone Wearable Power Suit-Development and Availability, Journal of Robotics and Mechatronics, 17, 5, 575-583 (2005)

5. Y. Nagata ed., Soft Actuators -Forefront of Development, NTS Ltd., 291-335 (2004).

6. F. Zhao,S. Dohta and T. Akagi, Development and Analysis of Small-sized Quasi-servo valves for Flexible Bending Actuator, Tansactions of the JSME (C), 76, 772, 3665-3671, (2010)

7. Y. Moriwake, T. Akagi, S. Dohta and F. Zhao, Development of low-cost pressure control type quasi-servo valve using embedded controller, Journal of Procedia Engineering, 41, 493-500 (2012)

8. S. Shimooka, S. Dohta, T. Akagi, Y. Moriwake and F. Zhao, Estimation of Pressure Control Performance in Low-Cost Quasi-Servo Valve Using Embedded Controller, Lecture Notes in Electrical Engineering 293, Springer, 1, 359-366 (2014) 